\title{
WINNING THE WAR ON TERROR: SUPPLY-SIDE PERSPECTIVE
}

\author{
Todd Sandler \\ Department of Economics \\ School of Economic, Political \& Policy Sciences \\ University of Texas at Dallas \\ Richardson, TX 75080 \\ USA \\ tsandler@utdallas.edu \\ Tel: 1-972-883-6725
}

May 2012

\begin{abstract}
This article introduces a supply-side perspective to the study of counterterrorism, where terrorists are viewed as combining terrorist attacks to achieve an aggregate output (e.g., social anxiety). With this novel approach, the elasticity of substitution, associated with the terrorists' production function, becomes a key determinant of the effectiveness of deterrence. If this elasticity is large, then countermeasures have very limited effectiveness when directed at a single mode of attack. If, in contrast, attack modes are complements, focused countermeasures can completely eliminate terrorists' gains. Counterterrorism measures are more effective when terrorist campaigns display little diversity of attacks. The article also identifies when proactive policies are more effective than defensive policies. The supply-side perspective gives a new pessimistic view to benevolence, which reduces the cost of nonterrorist activities.
\end{abstract}

Keywords: Benevolence; Deterrence; Elasticity of substitution; Other production parameters; Proactive measures; Supply-side perspective; Winning the war on terror

JEL codes: D24, D74, H56 


\section{WINNING THE WAR ON TERROR: SUPPLY-SIDE PERSPECTIVE}

\section{INTRODUCTION}

The application of rational-actor models to the study of terrorism dates back to Landes (1978), who applied the economics of crime and punishment to the study of hijackings in the United States. In particular, he showed that potential terrorist hijackers weighed the expected costs and benefits when determining whether to engage in a skyjacking. Landes (1978) found that a greater probability of apprehension, a greater likelihood of conviction, and a longer prison sentence deterred US hijackings. Also, he established that the installation of metal detectors in January 1973 served as an important deterrent of skyjackings. Sandler et al. (1983) allowed for rational strategic interactions among terrorists and targeted governments, where these adversaries took actions that affected the other's optimizing choices. Other articles that applied rationalactor models to the study of terrorism followed, with a huge increase in such analysis in economics, political science, and related fields after September 11, 2001 (hereafter, 9/11).

Among other issues, this literature investigated policy-induced substitution or transference that may result from ill-conceived counterterrorism policies. Using a household production function approach, ${ }^{1}$ Enders and Sandler (1993) showed that actions taken to thwart one mode of terrorist attack may lead terrorists to engage in other modes of attack with more harmful consequences. For example, fortification of embassies resulted in fewer attacks against embassy grounds, but more assassinations of embassy officials in unsecured venues (Enders and Sandler, 1993). ${ }^{2}$ Metal detectors greatly reduced skyjackings, but increased other types of hostage incidents (Enders and Sandler, 1993, Enders et al., 1990a, 1990b;). In a subsequent analysis, Enders and Sandler (2012) found that metal detectors actually increased the number of terrorist incidents that resulted in casualties, an unintended negative consequence. Target transference follows a similar line of reasoning. That is, public actions to protect officials and 
the military, and private actions to protect business targets resulted in terrorists shifting their attacks to private parties, which is the most difficult target type to defend (Brandt and Sandler, 2010, 2012).

In an important rational-actor article, Frey and Luechinger (2003) suggested a novel way to fight terrorism; namely, benevolence. These authors argued that benevolence, which reduces the relative price of nonterrorist actions (e.g., legitimate means of protests or political actions), may be preferable to raising the relative cost of terrorist attacks through deterrence. Frey and Luechinger (2003) indicated that benevolence may result in less terrorism and violent confrontations for society, as well as more consumption gains for the terrorists. As such, both society and the terrorists may prosper - i.e., a positive-sum outcome may follow. In a subsequent article, Anderton and Carter (2005) applied consumer theory (and Slutsky’s equation in particular) to show that benevolence need not result in less terrorism. In fact, terrorism will increase if the composite consumption good of the terrorists is price inelastic, which is a likely scenario.

All previous work on policy-induced substitutions, including that of Frey and Luechinger (2003) and Anderton and Carter (2005), used a utility-based approach (see, e.g., Bier et al., 2007; Enders, 2007; Enders and Sandler, 2004; Sandler and Arce, 2007). Even the household production function approach of Enders and Sandler (1993) is utility based, because the terrorists' utility is being maximized in terms of basic commodities. This has the disadvantage of ignoring the impact of policy-induced transference on the well-being of the general public, because the welfare in the model is that of the terrorists, not that of society. The purpose of the current article is to take a radically different approach by examining policy-activated transference from a supply-side perspective using concepts from the theory of cost and production. Here, terrorists are viewed as allocating scarce resources to their activities in order 
to achieve an output or campaign goal, subject to a cost constraint. In this framework, if the authorities are able to limit some aggregate measure of terrorist output (say, societal anxiety), then society must be better off. This aggregate output measure may be a composite of casualties (death and injured), property damage, and risk, which provides an overall measure of societal anxiety, not unlike the life satisfaction concept of Frey et al. (2009). Policy-induced transference would be judged by how the aggregate measure of terrorist output changes. Our alternative perspective provides numerous policy insights in "winning the war on terror" that are unrecognized to date. ${ }^{3}$ In particular, the analysis indicates when it is desirable for the authorities to target a single mode (or target) of terrorist attack, and when it is, instead, preferable to target multiple modes of terrorist attacks. The analysis also shows when it is best to destroy terrorist resources through proactive measures. These and other counterterrorism policy decisions are shown to hinge on the elasticity of substitution associated with the terrorist group's output function. By appealing to cost-output considerations, this new approach can draw on duality for further counterterrorism insights about how to limit terrorist outputs. The alternative approach here paints a more hopeful picture in addressing specific terrorist threats. Another purpose of the article is to reexamine the important issue of benevolence through the lens of this supply-side perspective. Benevolence is shown to increase terrorism when substitution among terrorist modes of attack is significant, if nonterrorist activity is an inferior input. This is a likely scenario for terrorist groups. When terrorist and nonterrorist activities are complements, benevolence must necessarily increase terrorism.

The remainder of the article contains six sections. The next section reviews the standard utility-based approach to transference. A brief review of Anderton and Carter (2005) is also provided. The following two sections present the supply-side perspective and the importance of the elasticity of substitution, respectively. Policy conclusions are then drawn, followed by a 
supply-side analysis of benevolence. The final section draws concluding remarks.

\section{UTILITY-BASED APPROACH TO COUNTERTERRORISM}

The standard utility-based analysis of terrorist transference involves the choice among alternative modes (e.g., hostage taking and bombings) or targets of attack (e.g., officials or private parties). Typically, a terrorist group must divide its efforts between nonterrorist and terrorist activities to achieve its intended political change. Once the group has decided this subdivision, it then needs to determine the composition of its campaign, which is the mix of terrorist attacks to use. More advanced analysis can treat these decisions as a two-stage process. I first consider a case where the terrorist group only engages in terrorist attacks that involve either hostage taking or bombings.

[Figure 1 near here]

In Figure 1, hostage-taking incidents are placed on the $y$-axis, while bombings are placed on the $x$-axis. The terrorist group initially faces budget constraint $X X$, whose equation is

$$
P_{H} H+P_{B} B=R,
$$

where $P_{H}$ and $P_{B}$ are the unit prices of hostage-taking and bombing incidents; $H$ and $B$ are the number of hostage-taking and bombing events of a uniform type; and $R$ denotes the group’s current resources. In Figure 1, the terrorist group maximizes its utility at point $A$, where its budget constraint is tangent to indifference curve $U_{0}$. If the authorities raise the price of hostage taking, then the budget constraint will move downward along the $y$-axis, pivoting from intercept $X$ on the $x$-axis, as shown, with a new optimum at $E$ on a lower indifference curve $U_{1}$. This price increase can arise from stiffer prison sentences for hostage taking or the installation of metal detectors in airports, which make skyjackings (a type of hostage incident) more difficult. The movement from $A$ to $E$ in Figure 1 is made up of a substitution effect ( $A$ to $D$ ), in which the 
terrorists reduce the number of hostage-taking incidents and increase the number of relatively cheaper bombings. The income effect ( $D$ to $E$ ) indicates a decrease in both hostage taking and bombings, since both activities are displayed as income normal.

In Figure 1, the overall effect is a decrease in hostage taking and an increase in bombings. The terrorists are worse off by this deterrence policy; however, the true impact on social wellbeing is unknown. If, for example, hostage taking results in few deaths, while bombings lead to a larger number of deaths, then this policy-induced substitution may make society worse off. With the installation of metal detectors in 1973, skyjackings went way down but other types of hostage or terrorist incidents increased greatly (Enders and Sandler, 2012). When first introduced in the 1980s, this utility-based analysis cautioned that deterrence can result in a different mix of terrorist attacks with, at times, undesirable or even dire consequences. The analysis also indicated that this worrisome substitution can be avoided by either reducing terrorist resources (a form of proactive policy) or increasing the prices of all modes of attack proportionately.

Frey and Luechinger (2003) and Anderton and Carter (2005) investigated the choice of nonterrorist and terrorist activities in response to deterrence or benevolence policies, both of which involve an increase in the relative price of terrorist acts. In their analysis (not displayed here), a composite nonterrorist good $(C)$ is placed on the vertical axis, while a generic terrorist attack $(T)$ is placed on the horizontal axis. Deterrence raises the relative price of terrorist acts and pivots the terrorist budget constraint in along the horizontal axis, keeping the constraint's vertical intercept fixed. ${ }^{4}$ If both activities are normal goods, deterrence will reduce terrorism and may also decrease the composite good. The latter occurs when the effect of reduced real income on the composite good dominates the substitution-induced increase in the composite good. Benevolence, or the lowering of the relative price of the composite good, results in a 
controversy. Frey and Luechinger (2003) depicted benevolence as potentially lowering the level of terrorism when the price-consumption curve is negatively sloped. If, however, the priceconsumption path is positively sloped, then Anderton and Carter (2005) demonstrated that benevolence leads to an increase in nonterrorist and terrorist activities. This follows when the composite nonterrorist good is price inelastic.

With the help of the cross price Slutsky equation, they showed that this latter outcome is anticipated. The relevant Slutsky equation is

$$
\varepsilon_{T C}=\sigma_{T C}-\alpha_{C} \eta_{T}
$$

where $\varepsilon_{T C}$ is the cross price elasticity of terrorism with respect to the price of the composite good; $\sigma_{T C}$ is the compensated cross price elasticity of terrorism; $\alpha_{C}$ is the average propensity to consume the composite good; and $\eta_{T}$ is the income elasticity of terrorism. If $\varepsilon_{T C}$ is negative, then the two activities are gross complements, and benevolence will increase terrorism as both activities increase. In (2), the compensated cross price elasticity is necessarily positive, given the two-good scenario. For normal goods, the goods are gross complements when the budget share spent on the composite good is substantial and $\sigma_{T C}$ is not too large. The latter is likely because the substitution possibilities between terrorism and all other activities are apt to be quite limited. Hence, Anderton and Carter (2005) are skeptical that benevolence will generally decrease terrorism. The Frey and Luechinger (2003) scenario is more likely for a terrorist group with a political wing (e.g., Hezbollah and Hamas), where resources are allocated between terrorist and nonterrorist (political) activities. This follows because $\sigma_{T C}$ permits more substitution possibilities.

\section{SUPPLY-SIDE PERSPECTIVE}


In this supply-side approach, terrorists are conceptualized as engaging in a terrorist-campaign to produce an aggregate output - e.g., societal anxiety - which is an aggregate index for casualties, property losses, and other negative consequences. I consider the case of a single output; however, the analysis can be extended to allow for multiple outputs based on the theory of multiproduct firms. The terrorist group chooses a mix of terrorist attacks to achieve an output level at minimum cost. ${ }^{5}$ For conceptual clarity, the terrorist group is characterized as choosing between hostage taking and bombings. In Figure 2, output level $Q_{0}$ is achieved at minimum cost at point $A$, where isocost line $C_{1}$ is tangent to isoquant $Q_{0}$. The slope of $C_{1}$ is $-P_{B} / P_{H}$. These individual prices depend not only on the available technology but also on counterterrorism measures.

[Figure 2 near here]

In Figure 2, the government has taken measures to raise the price of hostage taking, which, in turn, make the isocost line flatter. The new point of cost minimization is $D$, where flatter $C_{2}$ is tangent to isoquant $Q_{0}$. To compare $C_{1}$ and $C_{2}$, I draw isocost line $C_{3}$ parallel to $C_{2}$ through intercept $F$, whose value is $C_{1} / P_{B}$. Since $P_{B}$ has not changed, we know that $C_{1}=C_{3}$. Moreover, $C_{2}>C_{1}=C_{3}$ because cost $C_{2}$ is displaced further from the origin than $C_{3}$. This indicates that counterterrorism forces the terrorists to move from their cost-minimization combination of attacks, thereby resulting in the same terrorist output costing more. This is necessarily a good outcome for society and a bad outcome for the terrorists. If the terrorist group still spends $C_{1}=C_{3}$, then its aggregate output measure or loss for society is lower and corresponds to the isoquant (not displayed) tangent to $C_{3}$.

From a supply-side perspective, counterterrorism actions take terrorists out of their comfort zone by making them use a less ideal campaign combination, thus resulting in less losses 
for society. Hence, policy-induced transference comes at a cost to terrorist groups as they must find a different, less-desirable campaign strategy. Consequently, deterrent countermeasures have a positive payoff that is often ignored in the literature. In the very long run, technological innovations can lower the cost curve of the terrorist group.

One downside from counterterrorism may arise if actions by the authorities force the terrorists to innovate to circumvent countermeasures. Such innovations may follow from the introduction of new technological barriers - e.g., using plastic guns to escape metal detectors or placing bombs in a body cavity to fool a whole-body scanner.

\section{Numerical Example}

Consider a constant returns to scale Cobb-Douglas production function:

$$
Q=A H^{1 / 2} B^{1 / 2}
$$

where $A$ is a technology parameter, and $H$ and $B$ denote the number of hostage-taking incidents and bombings, respectively. Along the long-run expansion path, it follows that

$$
H=\frac{P_{B}}{P_{H}} B \text { and } B=\frac{P_{H}}{P_{B}} H
$$

With some algebra, ${ }^{6}$ the long-run cost function can be shown to equal

$$
C=\frac{2 Q}{A} \sqrt{P_{H} P_{B}}
$$

Given the linear homogeneity of the terrorist group's production function, the cost function is a linear ray out of the origin with a slope of $2 \sqrt{P_{H} P_{B}} / A$. An increase in the price of either mode of attack, stemming from counterterrorism actions, augments the long-run cost of the terrorists for any $Q$ level. If both $P_{H}$ and $P_{B}$ increase by a factor of $t$, then cost increases by the same factor. An increase in technology reduces the terrorist group’s cost. The theory can be easily 
extended to include more modes of attack and more complex production functions (see footnote 8).

\section{IMPORTANCE OF THE ELASTICITY OF SUBSTITUTION}

Once counterterrorism is viewed from the supply side, a key parameter becomes the elasticity of substitution, associated with the production function of the terrorists. This is easily shown graphically for two rather extreme cases. In Figure 3, the terrorist group’s production function permits little substitution between the two modes of attack. The initial cost-minimizing position is at $A$ with cost $C_{1}$. An increase in the relative cost of hostage taking results in the new costminimizing position migrating to $D$ on $Q_{0}$, where a large increase in bombings needs to make up for a small decline in hostage taking if terrorist output is to be maintained, owing to limited substitution possibilities. The cost increase from $C_{1}$ to $C_{2}$ is quite large, as reflected by the large distance between the parallel cost lines $C_{2}$ and $C_{3}$. Alternatively, the reduction in the output of terrorism, associated with the tangency between an isoquant (not shown) and isocost curve $C_{3}$, is substantial. In fact, terrorism may be pushed to near-zero levels. That is, counterterrorism aimed at one mode of attack may go a long way to reducing terrorism when targeted terrorists possess limited substitution possibilities. If, in the limit, hostage taking and bombings are perfect complements for some terrorist group, then counterterrorism measures that eliminate the use of one attack mode will effectively halt all attacks from the group. This follows because both modes of attack must be employed in fixed proportions to achieve an output level from the terrorist campaign. ${ }^{7}$ The lost of one attack mode takes away the group’s sought after impact.

[Figure 3 near here]

The opposite extreme is a large elasticity of substitution, as shown in Figure 4. The 
initial cost-minimizing position is at $A$, given the prices of the modes of attack. An increase in the relative price of hostage taking shifts the cost-minimizing position to $D$. The augmented cost associated with $C_{2}$ is modest, because the distance between $C_{2}$ and $C_{3}$ is rather small. This follows because one mode of attack can readily substitute for another, thereby stymieing the attempt by the authorities to reduce terrorism by making one mode of attack more costly.

[Figure 4 near here]

Next, suppose that hostage taking and bombings are perfect substitutes for producing the desired aggregate output of the terrorist group. In Figure 5, a specific output level of the terrorist group corresponds to a linear downward-sloping isoquant, such as $Q_{0}$. Further suppose that the relative price of bombings (i.e., $P_{B} / P_{H}$ ) exceeds the marginal rate of technical substitution (i.e., the negative slope of the isoquant), so that the cost-minimizing terrorist campaign involves just hostage taking at $A$. With a sufficient price rise in hostage taking, the cost-minimizing output jumps to the other corner on the isoquant at $D$, where only bombings are used. Both $A$ and $D$ have the same cost $C_{3}$, where $C_{1}=C_{3}$ and $C_{2}=C_{3}$, owing to the shared intercepts at $A$ and $D$, respectively. For perfect-substitute attack modes, counterterrorism directed at a single mode of attack is unable to raise the terrorist group's cost or lower its output. ${ }^{8}$ As shown in the next section, a different counterterrorism strategy is essential for substitute attack modes. If the terrorists rely on many modes of attack that are perfect or near-perfect substitutes, then counterterrorism is an even a greater challenge for governments.

[Figure 5 near here]

\section{POLICY IMPLICATIONS}

A terrorist group that relies on a diversified terrorist campaign with many alternative substitute 
modes of attack is best able to withstand the cost (and, hence output) consequences from the authorities targeting specific attack modes. The development of a varied terrorist campaign should bolster the group’s survival prospects. In an empirical analysis, Blomberg et al. (2011) found that terrorist groups that diversified their attacks survived significantly longer. These authors examined 367 terrorist groups for the 1970-2007 period, using event data drawn from the Global Terrorism Database (GTD) and group data drawn from Jones and Libicki (2008). To counter terrorist groups with diversified campaigns, the authorities must simultaneously target multiple attack modes to limit substitution possibilities. Another promising strategy is to reduce terrorist groups’ resources through attacks on their training facilities and infrastructure. Terrorists’ resources can also be curtailed by going after their supporters and sources of finance. Infiltrating groups or capturing terrorists would also limit resources.

If, however, the terrorists possess limited substitutability among attack modes, then targeting specific attack modes is an effective countermeasure. This is particularly true when terrorist modes of attack are complementary inputs, because curbing a single type of attack will effectively reduce two or more attack modes and decrease terrorist output or aggregate harm. When a terrorist group uses just one mode of attack (i.e., isoquants are horizontal or vertical), targeting that mode is obviously a fruitful policy. A counterterrorism strategy of limiting attack modes can pay off in the long run as the terrorist group’s diversity of attacks falls. A long-run policy concern is counterterrorism actions that induce terrorists to innovate new attack modes. Since the rise of the modern era of transnational terrorism in 1968, such innovations involved suicide car bombings and other types of suicide attacks being added to some groups' attack campaign (e.g. Hezbollah, Tamil Tigers, and Palestinian Islamic Jihad). Chemical terrorist attacks (e.g., the sarin attack on the Tokyo Subway in March 1995) are another innovation. Given that terrorist groups’ campaigns vary by their diversity and substitution 
possibilities, the best counterterrorism strategy differs greatly among groups. Some terrorist groups may be completely stymied by the government's action to make one mode of attack more difficult, while other groups may experience no hardship by such a focused policy. Because the composition of terrorist campaigns is readily observable, it is apparent for different terrorist groups whether a more broad-based proactive approach against their resources is needed. If a terrorist group has a diversified campaign, then technological barriers (e.g., metal detectors) may be rather ineffective yet expensive to deploy. This follows because such barriers are typically geared to stopping one mode of attack, which can be countered through terrorist transference.

\section{BENEVOLENCE FROM A SUPPLY-SIDE PERSPECTIVE}

I now return to the analysis of benevolence where a government reduces the relative price of nonterrorist activities of the terrorists, thereby making such nonviolent acts more attractive. Recall that Anderton and Carter (2005) emphasized that this policy would not reduce terrorism if the nonterrorism (composite) good is price inelastic.

[Figure 6 near here]

I first consider the case where terrorist and nonterrorist acts present significant substitution possibilities for the terrorists. In Figure 6, nonterrorist activities $(N)$ are placed on the $y$-axis and terrorist attacks $(T)$ are put on the $x$-axis. The initial cost-minimizing position is $A$, where the terrorist cost is $C_{1}$. Benevolence shifts the isocost curve to $C_{2}$ for which the terrorist group moves to $D$ when terrorist output is maintained at $Q_{0} . C_{2}$ is less than $C_{3}=C_{1}$ since $C_{3}$ is displaced to the right of parallel isocost line $C_{2}$, Hence, benevolence allows the terrorist group to achieve the same output at a reduced cost. This output measure may now include political change along with casualties and property losses. If the terrorist group spends 
the same amount as before, which is the likely scenario, then it moves to $E$ with greater terrorist attacks than at $D$. If, however, terrorist attacks are to increase compared to $A$, then the final position must move to a point like $E_{1}$. The movement to $E_{1}$ implies that nonterrorism activity is an inferior input for the terrorist group. This is a likely scenario for many terrorist groups that have resorted to violence. So the supply-side perspective stresses the input inferiority when the two types of activities are substitutable, while the utility-based perspective highlights price inelasticity and, consequently, the share of income devoted to terrorism. If, however, there is limited or no substitutability between the two kinds of activities (not shown), then the increased real income from the price decline in nonterrorist acts must necessarily increase terrorist attacks. ${ }^{9}$ The supply-side approach shows that if society is interested in limiting the output of the terrorist group - whether obtained through legitimate or illegitimate means, then benevolence necessarily worsens the well-being of society by promoting the agenda of the terrorist group. This may be particularly bad when the reduced price of nonterrorist acts results in more terrorism.

The nature of the terrorist group may determine whether the final outcome of benevolence is at $E$ or $E_{1}$ in Figure 6. If the terrorist group is more politically motivated with a strong political wing, then $E$ is the anticipated outcome. A more militant terrorist group is apt to end up at $E_{1} \cdot{ }^{10}$ In either case, society is worse off as the terrorist group circumvents the political process by gaining concessions through the threat of violence.

\section{CONCLUDING REMARKS}

This article views policy-induced transference of terrorist tactics from a supply-side perspective, where terrorist groups use their attack modes and/or political activities to gain an aggregate output (e.g. social anxiety) at least cost. This novel viewpoint highlights the importance of 
reducing terrorist attack diversity and substitutability. Government actions to raise the price of specific modes of attack may cause more harm to terrorist groups in certain well-defined circumstances than is appreciated in the literature. Given the small budgets that most terrorist groups have for operations (Enders and Sandler, 2012), counterterrorism actions that raise cost can be quite beneficial to society. For terrorist groups that only rely on violent actions, government measures to make one form of attack more difficult or costly typically reduce the output of the group unless it is able to obtain further resources. Counterterrorism policies aimed at specific attack modes are more effective when the elasticity of substitution, associated with the terrorists' production function, is near zero, or when the terrorists rely on a single attack mode. Such single-mode countermeasures are not effective when terrorist attack modes are near-perfect substitutes or terrorist campaigns are very diverse. In such situations, the authorities must be more proactive and go after the groups’ resources including their members. Alternatively, the government must mount broad-based countermeasures against a variety of attack modes. The results here imply that terrorist groups with diversified campaigns have better survival prognosis, consistent with Blomberg et al. (2011). Because larger terrorist groups are better able to diversify their attack, given their more varied expertise and resources, such groups present a formidable counterterrorism challenge to the authorities, who must institute proactive methods to reduce group size. ${ }^{11}$ When targeting terrorist groups, governments are more effective if they apprehend pivotal members (e.g., strategists or bomb makers), who facilitate a range of attacks.

The supply-side perspective may provide additional insights when other production parameters are investigated in future research. For example, economies of scale indicate the growth prospects of terrorist groups that can amass resources over time. Groups whose campaigns admit significant scale economies can see a doubling of attacks result in more than a doubling of output. ${ }^{12}$ The prospect of such scale effects makes it imperative for the authorities to 
limit a terrorist group's resources. A knowledge of the distribution parameter among attack modes can indicate how thwarting particular attack modes will differentially impact the output of a terrorist campaign.

With a supply-side perspective, this article also shows that benevolence raises concerns as terrorist groups' overall cost decreases. Because nonterrorist activities are likely inferior inputs for these groups, benevolence is anticipated to increase not only terrorist attacks, but also terrorist output, both of which lessen the welfare of society. Even a politically motivated terrorist group obtains greater output through benevolence. 


\section{ACKNOWLEDGEMENTS}

This research was funded, in part, by the US Department of Homeland Security (DHS) through the Center for Risk and Economic Analysis of Terrorism Events (CREATE) at the University of Southern California, grant number 2010-ST-061-RE0001. However, any opinions, findings, and conclusions or recommendations are solely those of the authors and do not necessarily reflect the view of DHS or CREATE. I have also profited from the remarks of an anonymous reviewer and Daniel Arce. 


\section{Footnotes}

1. With a household production function approach, terrorists are viewed as using various modes of attack as intermediate inputs to produce basic commodities, such as social anxiety or political change.

2. This was shown empirically with a vector-autoregression (VAR) analysis that investigated dynamic interactions among the time series of various terrorist modes of attack. Landes (1978) did not account for such substitutions.

3. I use the term, winning the war on terror, to relate to its presence in the media and to be somewhat provocative. I do not believe that terrorism can be eliminated now or ever; however, I do think that specific terrorist threats and groups can be eliminated.

4. The budget constraint is $P_{C} C+P_{T} T=R$, where $P_{C}$ and $P_{T}$ are the unit prices of the composite good and the terrorist activity, respectively.

5. By duality, this is the same as maximizing output subject to a cost constraint.

6. This follows by using (4) to substitute for $H$ in (3) to give

$$
B=\frac{Q}{A} \sqrt{\frac{P_{H}}{P_{B}}} .
$$

A similar substitution for $B$ in (3) yields

$$
H=\frac{Q}{A} \sqrt{\frac{P_{B}}{P_{H}}} .
$$

These expressions for $B$ and $H$ are then substituted into the cost function,

$$
C=P_{B} B+P_{H} H
$$

and simplified to derive (5).

7. The group's production function is $Q=\min (H, B)$, which equals zero when either hostage taking or bombings is zero. 
8. The influence of the elasticity of substitution, $\sigma$, on the cost function can be displayed for a constant elasticity of substitution (CES) production function,

$$
Q=\left[\lambda H^{\rho}+(1-\lambda) B^{\rho}\right]^{1 / \rho}
$$

where $\lambda$ and $(1-\lambda)$ are distribution parameters, and $\rho=(\sigma-1) / \sigma$ or $\sigma=1 /(1-\rho)$. The corresponding cost, $C$, function is

$$
C=\left[\lambda^{\sigma} P_{H}^{1-\sigma}+(1-\lambda)^{\sigma} P_{B}^{1-\sigma}\right]^{1 /(1-\sigma)} Q
$$

A standard result is that the elasticity of substitution between input prices is $1 / \sigma$. A small $\sigma$ in production makes for a large elasticity of substitution in cost.

9. I thank the anonymous referee for this insight.

10. On the distinction between politically-motivated and militant groups, see Arce and Sandler (2007).

11. This is consistent with the important analysis by Feinstein and Kaplan (2010), who showed that the authorities must act quickly to keep nascent groups small so that their campaign choice remains limited - i.e., devoid of large-scale or complex operations.

12. If the terrorist output is carnage or social anxiety, then a campaign reliant on suicide missions may possess such scale effects. 


\section{References}

Anderton, C.H. and Carter, J.R. (2005) On rational choice theory and the study of terrorism. Defence and Peace Economics 16(4) 275-282.

Arce, D.G. and Sandler, T. (2007) Terrorist signalling and the value of intelligence. British Journal of Political Science 37(4) 573-586.

Bier, V., Oliveros, S. and Samuelson, L. (2007) Choosing what to protect: Strategic defensive allocation against an unknown attacker. Journal of Public Economic Theory 9(4) 113131.

Brandt, P.T. and Sandler, T. (2010) What do transnational terrorists target? Has it changed? Are we safer? Journal of Conflict Resolution 54(2) 214-236.

Brandt, P.T. and Sandler, T. (2012) A Bayesian Poisson vector autoregression model. Political Analysis, 20( ) forthcoming.

Blomberg, S.B., Gaibulloev, K. and Sandler, T. (2011) Terrorist group survival: Ideology, tactics, and base of operations. Public Choice 149(3-4) 263-280.

Enders, W. (2007) Terrorism: An empirical analysis. In Handbook of Defense Economics, Volume 2, edited by T. Sandler and K. Hartley. Amsterdam: North-Holland, 815-866.

Enders, W. and Sandler, T. (1993) The effectiveness of anti-terrorism policies: A vectorautoregression-intervention analysis. American Political Science Review 87(4) 829-844.

Enders, W. and Sandler, T. (2004) What do we know about the substitution effect in transnational terrorism? In Research on Terrorism: Trends, Achievements, and Failures, edited by A. Silke. London: Frank Cass, 119-137.

Enders, W. and Sandler, T. (2012) The Political Economy of Terrorism, $2^{\text {nd }}$ Edition. Cambridge: Cambridge University Press.

Enders, W., Sandler, T. and Cauley, J. (1990a) Assessing the impact of terrorist-thwarting 
policies: An intervention time series approach. Defence Economics, 2(1) 1-18.

Enders, W., Sandler, T. and Cauley, J. (1990b) UN conventions, technology, and retaliation in the fight against terrorism: An econometric evaluation. Terrorism and Political Violence 2(1) 83-105.

Feinstein, J.S. and Kaplan, E.H. (2010) Analysis of a strategic terror organization. Journal of Conflict Resolution 54(2) 281-302.

Frey, B.S. and Luechinger, S. (2003) How to fight terrorism: Alternatives to deterrence. Defence and Peace Economics 14(4) 237-249.

Frey, B.S., Luechinger, S. and Stutzer, A. (2009) The life satisfaction approach to valuing public goods: The case of terrorism. Public Choice 138(3-4) 317-345.

Jones, S.G. and Libicki, M.C. (2008) How Terrorist Groups End: Lessons for Countering al Qa’ida, Monograph MG-741-1. Santa Monica: RAND.

Landes, W.H. (1978) An economic study of US aircraft hijackings, 1961-1976. Journal of Law and Economics 2(1) 1-31.

Sandler, T. and Arce, D.G. (2007) Terrorism: A game-theoretic approach. In Handbook of Defense Economics, Volume 2, edited by T. Sandler and K. Hartley. Amsterdam: NorthHolland, 775-813.

Sandler, T., Tschirhart, J. and Cauley, J. (1983) A theoretical analysis of transnational terrorism. American Political Science Review 77(1) 36-54. 


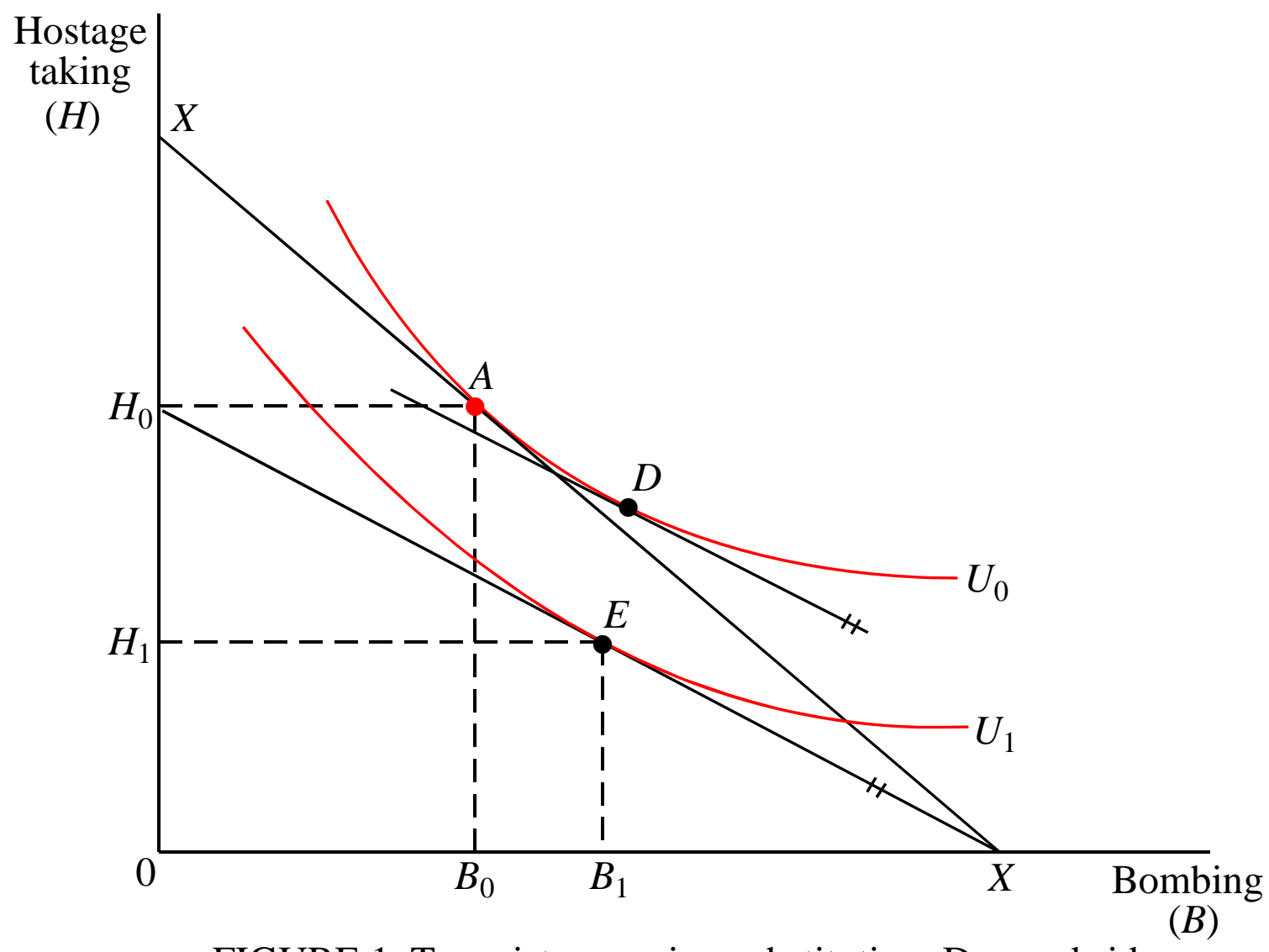

FIGURE 1 Terrorist campaign substitution: Demand side 


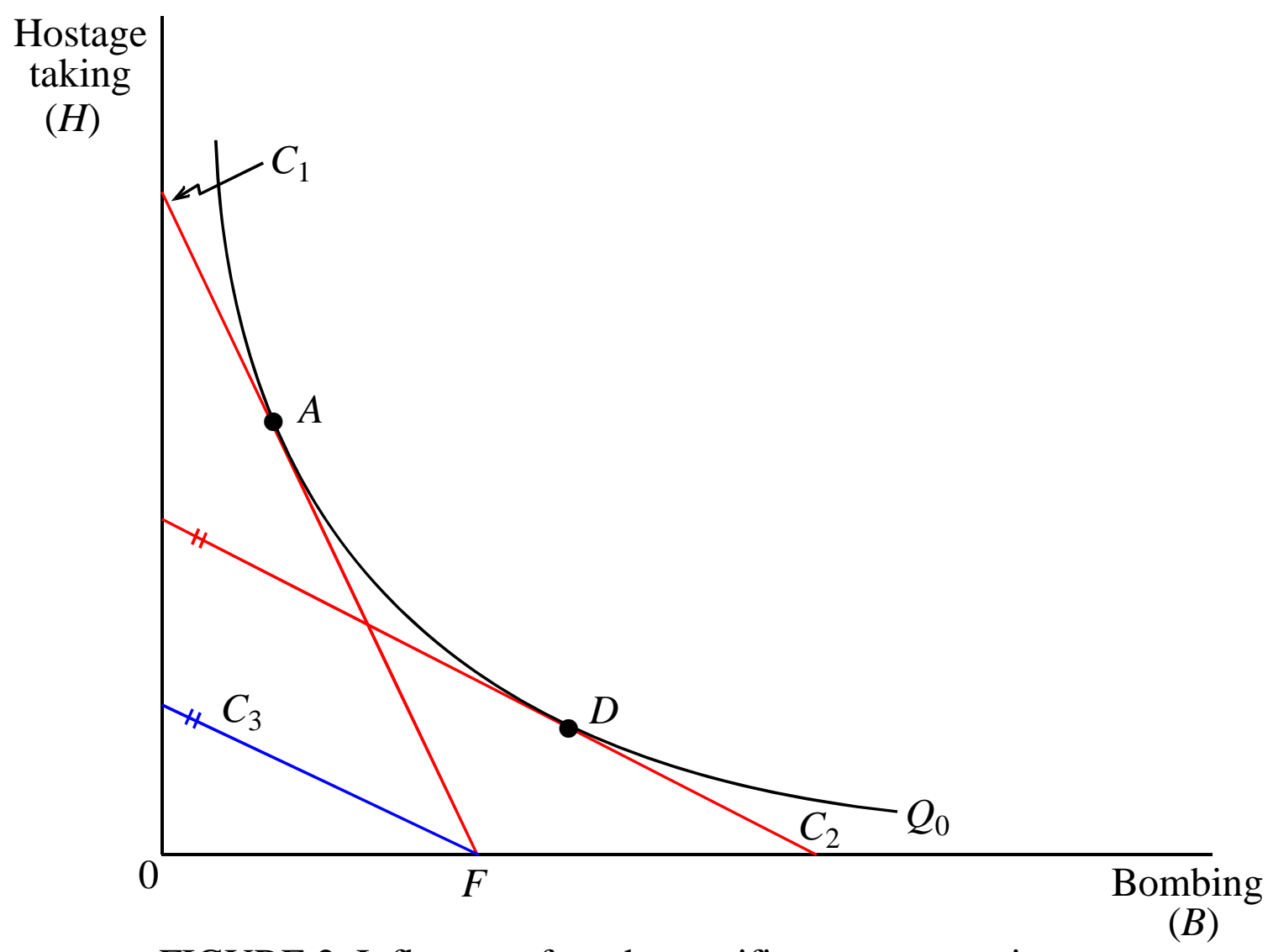

FIGURE 2 Influence of mode-specific counterterrorism on costs 


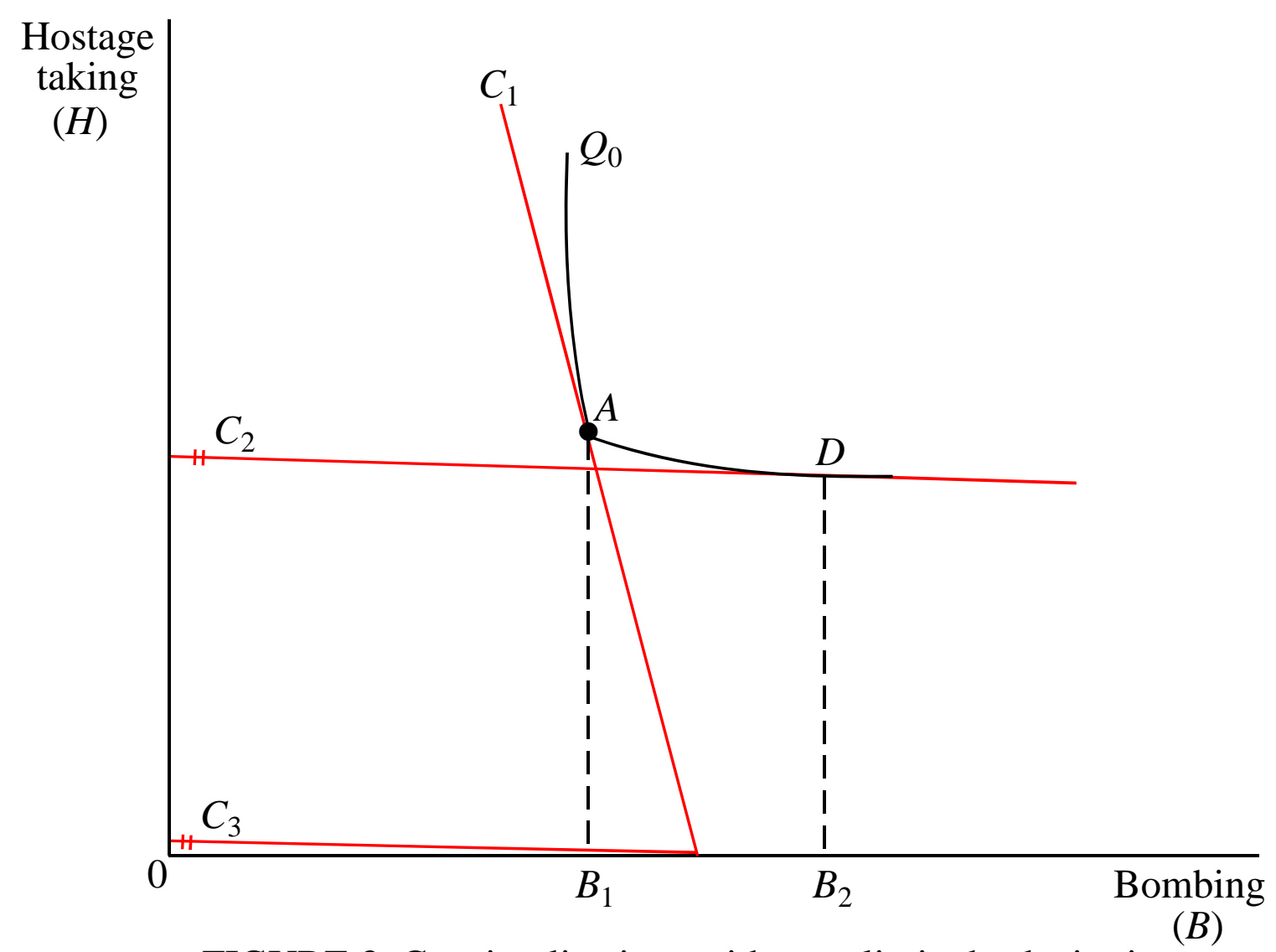

FIGURE 3 Cost implications with very limited substitution 


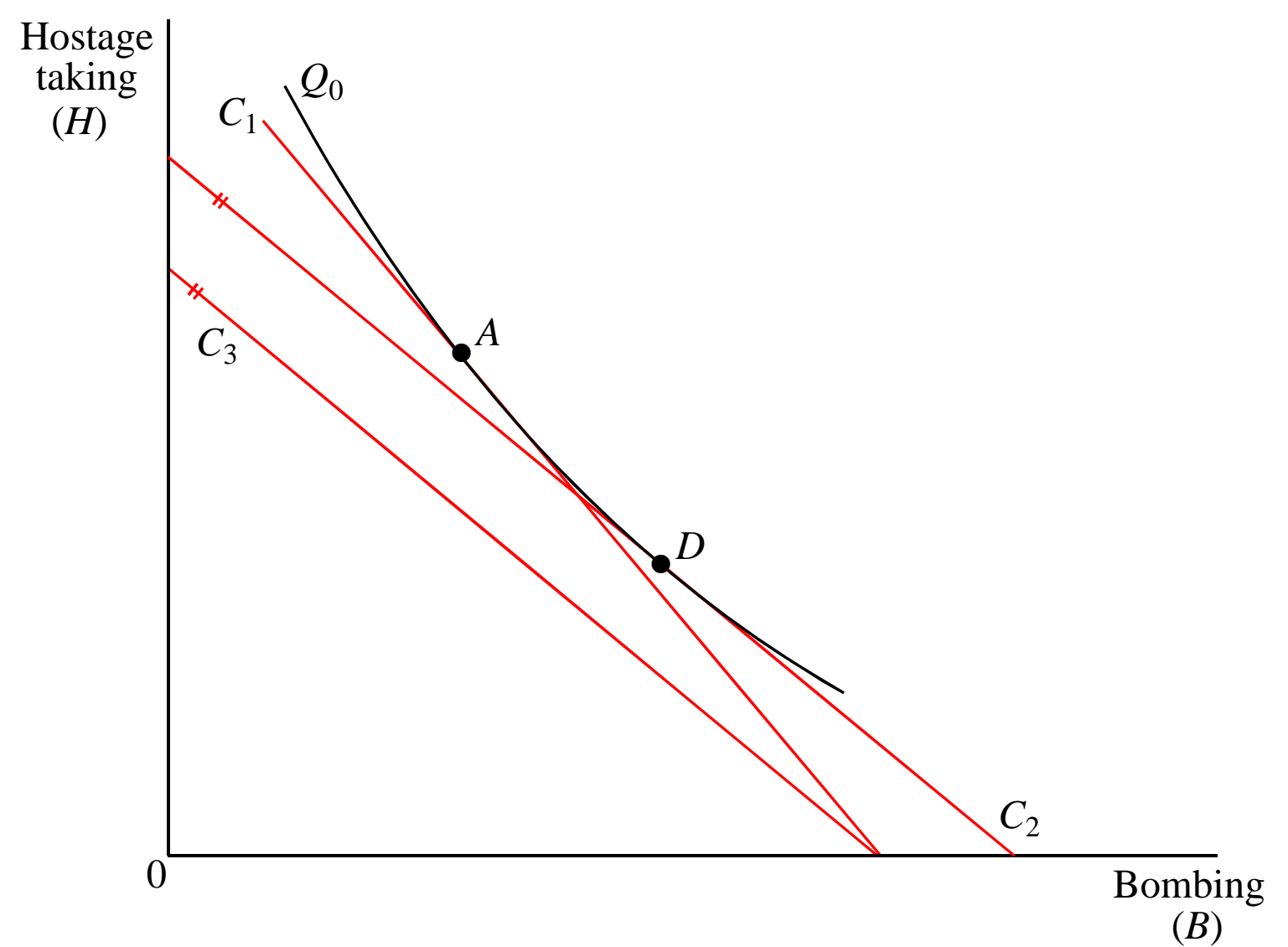

FIGURE 4 Cost implications with large substitution possibilities 


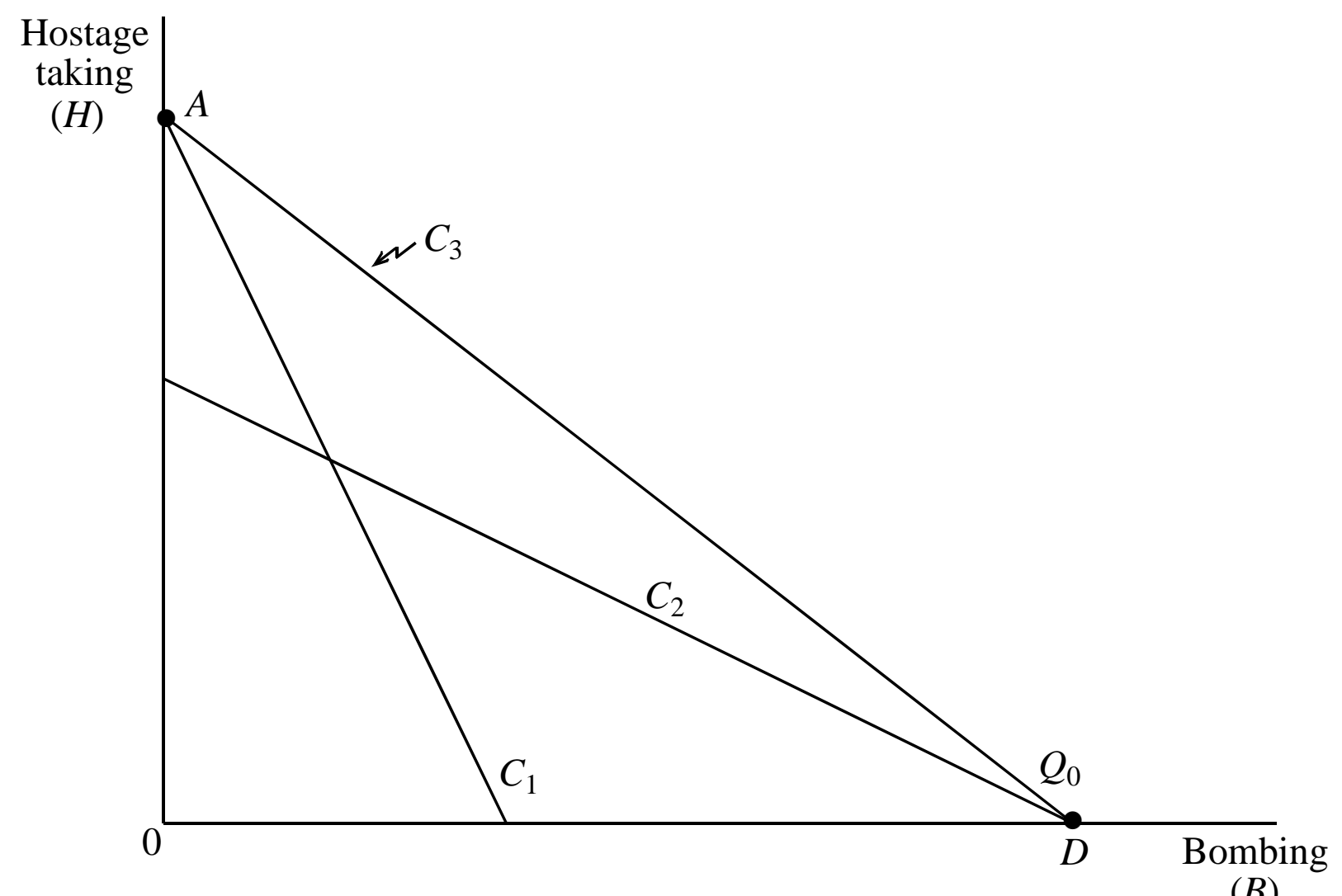

FIGURE 5 Corner solutions with perfect-substitute inputs 


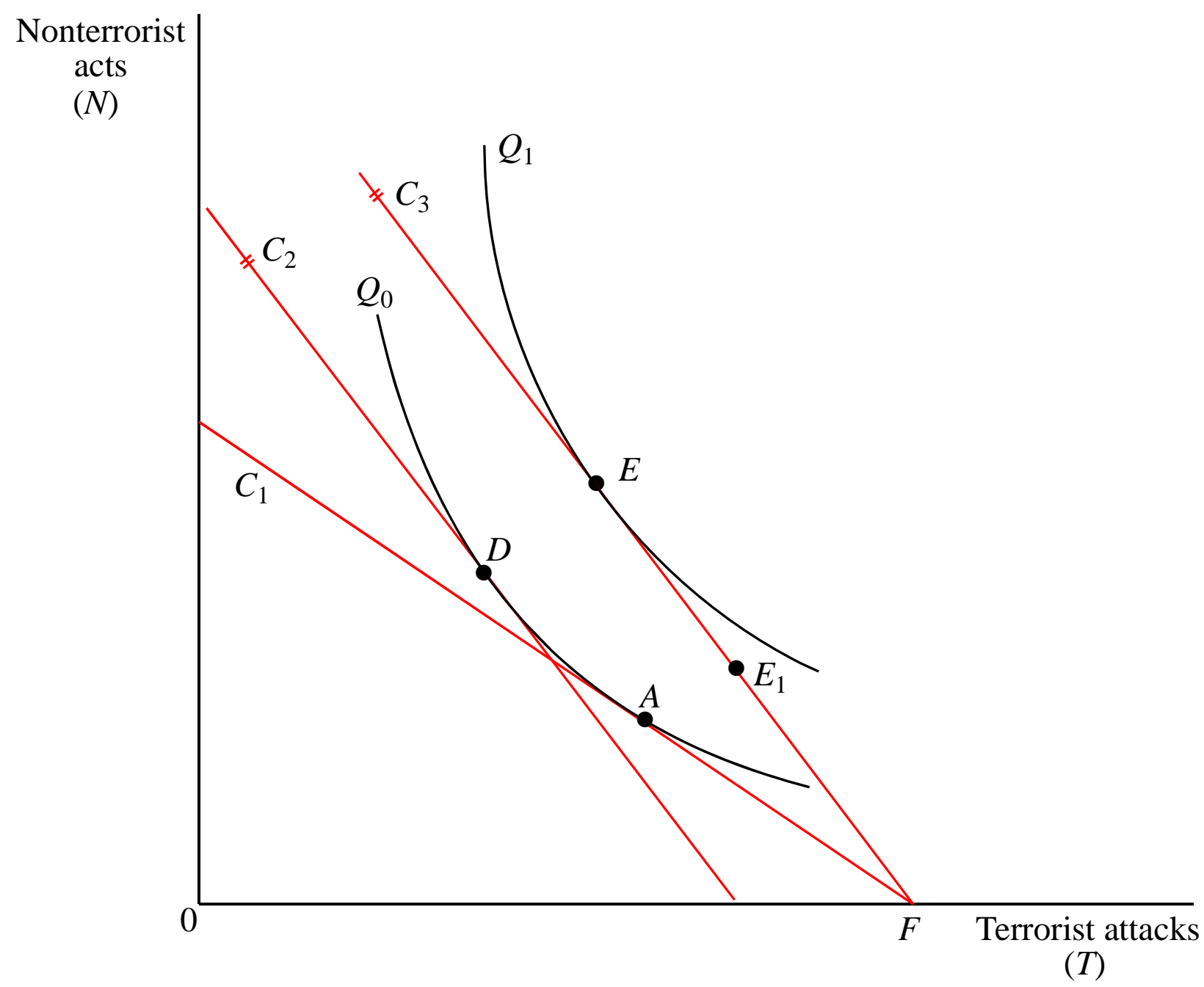

FIGURE 6 Cost implications for Anderton-Carter's analysis 